\title{
GARANTISMO, ATIVISMO E O ESTUPRO DE VULNERÁVEL: REFLEXÕES HIPOTÉTICAS A PARTIR DO "FAZER ATIVISTA" DOS JUIZADOS DA INFÂNCIA E DA JUVENTUDE
}

\author{
GUARANTEEISM, ACTIVISM AND THE RAPE OF VULNERABLE: HYPOTHETICAL \\ REFLECTIONS FROM THE “ACTIVIST CONDUCT” OF JUDGES OF CHILDHOOD AND \\ YOUTH
}

\section{Olegário Gurgel Ferreira Gomes}

Promotor de Justiça do Ministério Público do Estado do Rio Grande do Norte e professor do Departamento de Direito da Universidade do Estado do Rio Grande do Norte (UERN), tendo publicado o livro "Justiça Juvenil: socioeducação como prática da liberdade". Mestre em Direito pela Universidade de Lisboa.

E-mail: olegariofgomes@gmail.com

\section{Nestor Eduardo Araruna Santiago}

Doutor em Direito Tributário, com estágio Pós-Doutoral em Direito pela Universidade do Minho, Portugal. Professor Titular do Programa de Pós-Graduação Stricto Sensu em Direito Constitucional da Universidade de Fortaleza (UNIFOR). Professor Adjunto IV do Curso de Graduação em Direito pela Universidade Federal do Ceará (UFC).

E-mail: nestorsantiago@unifor.br

Recebido em: 16/12/2019

Aprovado em: 18/08/2020

RESUMO: A Justiça da Infância e Adolescência parece projetar um natural ativismo como decorrência direta de seus fins de proteção. Afinal, o que mais caracteriza a justiça especializada é o esforço em promover direitos fundamentais, agindo de forma a salvaguardar a criança na integralidade de suas posições jurídicas. $\mathrm{O}$ "fazer ativista" representa uma importante oportunidade para entender o papel da jurisdição, principalmente no que diz respeito aos fins do Poder Judiciário. O objetivo do artigo é investigar a suposta natureza ativista da Justiça da Infância e Adolescência, analisando situações hipotéticas acerca do crime de estupro de vulnerável, tema com o qual se espera contrapor os valores de proteção e de imparcialidade. Serão analisadas três circunstâncias, a liberdade sexual, a relação entre família e tutela estatal e os abusos que incidem sobre o consentimento para o sexo. A abordagem metodológica é a qualitativa, com pesquisa bibliográfica e documental. Espera-se, ao final, concluir que a estrita legalidade, na concepção conferida pelo garantismo, oferece meios hermenêuticos aptos a conciliar a proteção da lei com a proteção dos direitos de crianças e adolescentes.

Palavras-chave: Justiça da Infância e da Adolescência. Ativismo. Garantismo. Estupro de vulnerável.

ABSTRACT: The Child and Adolescent Justice seems to project a natural activism as a direct result of its protective purposes. After all, what most characterizes this specialized justice is the effort to promote fundamental rights, acting in a way that safeguards the child in all his legal positions. "Activist conduct" represents an important opportunity to understand the role of 
jurisdiction, especially with regard to the purposes of the judiciary power. The aim of the article is to investigate the supposed activist nature of the Justice of the Childhood and Adolescence, analyzing hypothetical situations about the crime of rape of vulnerable, subject with which is expected to oppose the values of protection and impartiality. Three circumstances will be examined, sexual freedom, the relationship between family and state protection and abuses of consent to sex. The methodological approach is qualitative, with bibliographic and documentary research. It is expected, in the end, to conclude that strict legality, in the conception conferred by guaranteeism, offers hermeneutic means capable of reconciling the protection of the law with the protection of the rights of children and adolescents.

Keywords: Child and Adolescent Justice. Activism. Guaranteeism. Vulnerable rape.

SUMÁRIO: Introdução; 1 O consentimento no crime de estupro de vulnerável; 1.1 Autonomia para o sexo; 1.2 Família e tutela da liberdade sexual; 1.4 Abusos no consentimento; 1.4 Avaliação dos resultados; $2 \mathrm{O}$ ativismo e a perspectiva garantista do Direito; Conclusão; Referências.

\section{INTRODUÇÃO}

O dever geral de proteção que anima o Direito da Criança e do Adolescente não exime a atividade jurisdicional. Muito pelo contrário, o Poder Judiciário é tão devedor quanto qualquer outro órgão estatal de prestar a assistência necessária à pessoa em desenvolvimento, tal a força de dispositivos constitucionais e infraconstitucionais que qualificam a ordem jurídica brasileira.

A obrigação de proteger abrange duas qualidades, a prioridade absoluta, nos termos do que determina o artigo 227 da Constituição Federal de 1988 (CF), e a proteção integral, na exata expressão do artigo $1^{\circ}$ da Lei n. 8.069, de 13 de julho de 19901, que dispõe sobre o Estatuto da Criança e do Adolescente (ECA). São dois valores que fazem da atitude de proteger um complexo de atitudes: cuidar, promover, desenvolver, amar, educar, alimentar, prevenir, acautelar, resguardar, vigiar, dentre outras ações que dão sentido às diretrizes que coordenam a legislação brasileira, todas voltadas a erigir e fortalecer a ideia central de que toda criança goza de precedência e completude.

Isso resulta em duas consequências práticas: a) o exercício da jurisdição deve ter alinhamento obrigatório com a proteção dos direitos da criança, não podendo editar atos que contrariem essa máxima, ainda que indiretamente; b) a interpretação dos fatos e do direito não pode afrontar o ideal de bem-estar infantil, que se impõe como uma linha dirigente e obrigatória aos diferentes métodos hermenêuticos.

Mas, sendo assim vitais as atitudes e os valores de proteção à infância em razão das diretrizes normativas constitucionais e infraconstitucionais, o que se impõe conclusivo é a feição diferenciada da Justiça da Infância e Adolescência, que, ao contrário das demais áreas de atribuições do Poder Judiciário apresentaria o caráter ativista como um elemento natural, ou seja, uma decorrência direta de sua natureza protetiva. Teria assim um grau de inexorável ativismo2 na promoção dos direitos fundamentais, não podendo se afastar desta perspectiva sem perder com isso

1 Os princípios da prioridade absoluta, da proteção integral e do melhor interesse compreendem as diretrizes centrais do Direito da Criança e do Adolescente, harmonizando a interpretação dos dispositivos legais e conferindo coerência ao microssistema jurídico que sobressai da Lei n. 8.069/1990.

2 Para o conceito de ativismo judicial, conferir Jorge Neto (2014, p. 513): “O ativismo judicial no sentido de maior ou mais ousada criação do direito por parte dos juízes é, portanto, uma decorrência lógica do pós-positivismo, que se caracteriza pela normatização de conteúdos axiológicos por meio dos princípios, normas de textura aberta, isto é, de conteúdos não imediatamente definíveis. A concretização dos princípios, no momento da aplicação do Direito, passa necessariamente pelo preenchimento da norma por meio da criação de significantes, não mais pela mera descoberta significados. Os juízes deixam de ser meros intérpretes de um texto normativo com conteúdo mais ou menos evidente e passam a ser criadores do conteúdo dos princípios". 
a condição ontológica que lhe serve de distinção: o imperativo prioritário de salvaguardar a criança na integralidade de suas posições jurídicas. A diferenciação seria portanto a priori, existindo já no conceito de jurisdição infantil, o que justificaria, por exemplo, ações atípicas de promoção de direitos independente de requerimento das partes3.

Dito isso, inevitável questionar se há meios de conciliar o dever de proteger com o dever de isenção. Nada obstante os fins que persegue, é importante investigar se a Justiça especial de crianças e adolescentes de algum modo harmoniza os princípios da prioridade absoluta e da proteção integral com o princípio da imparcialidade do juiz (artigo $5^{\circ}$, incisos LIII e LIV, da CF).

Um tema que pode esclarecer a dicotomia entre proteção e isenção na jurisdição infantojuvenil4 é o da liberdade sexual na menoridade, eis que contrapõe os dois valores em destaque com diferentes soluções a depender da situação concreta em análise. Assim, é pertinente dirigir o debate ao crime de estupro de vulnerável, tipificado no artigo 217-A, do Decreto-lei n. 2.848, de 7 de dezembro de 1940 (Código Penal Brasileiro - CP), com redação conferida pela Lei n. 12.015, de 7 de agosto de 2009. A escolha é estratégica e realça o viés constitucional do problema, considerando que a prevalência de uma diretriz sobre outra, seja qual for o preceito vitorioso, implica resultados gravosos para as pessoas envolvidas. Afinal, tanto a proteção da infância quanto a proteção da liberdade individual são bens jurídicos de elevada magnitude.

A pergunta essencial se reduz, então, aos seguintes termos: o juiz, decidindo posições jurídicas de crianças e adolescentes vítimas de violência sexual, deve conferir prioridade absoluta e proteção integral aos direitos destes ou seguir a estrita legalidade? Em outras palavras, deve ponderar em cada caso concreto os valores contrapostos da proteção e da imparcialidade ou simplesmente buscar a objetividade de uma atuação garantista e técnica?

As indagações serão respondidas a partir de três situações-problemas: a primeira envolvendo a autonomia para o sexo no crime de estupro de vulnerável; a segunda tratando da relação entre família e tutela da liberdade sexual; e a última abordando a delicada identificação de abusos que incidem sobre o consentimento para o sexo.

Eis aí o objetivo geral do artigo, analisar casos concretos hipotéticos de violência sexual contra crianças e adolescentes para definir a extensão da natureza ativista da Justiça da Infância e Adolescência e seu esforço em superar essa postura em favor de um agir democrático e estruturado na lei. Como objetivos específicos é devido apontar os seguintes: a) delimitar o papel do garantismo na jurisdição especial; b) discutir o método hermenêutico apropriado; c) apurar as razões segundo as quais os valores de proteção e imparcialidade combinam soluções diferentes a depender da situação em estudo; d) propor caminhos para a flexibilização do princípio da estrita legalidade; e) oferecer soluções teóricas para problemas práticos do Direito da Criança e do Adolescente.

O método é o qualitativo, com pesquisa bibliográfica e documental. Tem sua base na lógica indutiva, já que parte de aspectos particulares de um fato para alcançar conclusões gerais. A

3 Observe-se a iniciativa do magistrado em produzir estudo técnico de equipe multidisciplinar nas ações socioeducativas, nos termos do artigo 186 , caput, e $\S 4^{\circ}$, da Lei n. 8.069/1990. Outro exemplo é a previsão de instauração de procedimento de apuração de irregularidades em entidade governamental e não-governamental mediante portaria da autoridade judiciária (artigo 191 da referida lei). É de citar ainda as atribuições regulatórias do juiz da infância e adolescência previstas no artigo 149 da lei estatutária, disciplinando a entrada e a participação de crianças e adolescentes em eventos esportivos e culturais, e a autorização do artigo 153 desse mesmo diploma legal para investigar fatos e ordenar de ofício as providências necessárias. São ações atípicas como essas que fazem das palavras de Amaral e Silva (1994, p. 270) uma reflexão imprescindível: "Sistema de justiça não faz assistência social, administra justiça".

4 Trata-se de um dilema antigo na jurisdição infantil. Até o advento da CF prevalecia na doutrina especializada a ideia de parcialidade do "juiz de menores", que deveria atuar antes como um bom pai do que propriamente como juízo técnico, agindo de ofício e inquisitivamente na proteção da infância e adolescência. O paternalismo foi ao longo de todo o século XX a característica marcante do exercício jurisdicional, autorizando iniciativas estranhas ao exercício da magistratura. É o que explica Machado (2003, p. 46): "E agindo com os poderes do bom pai de família, evidentemente o juiz de menores não está sujeito ao princípio da inércia da jurisdição e muito menos ao da imparcialidade, nem se deve submeter ao cumprimento do formalismo garantista das normas processuais". 
técnica contempla a definição de um problema estrutural, no caso em exame o embate entre valores constitucionais, para tentar descobrir novas razões que facilitem o entendimento do tema.

\section{O CONSENTIMENTO NO CRIME DE ESTUPRO DE VULNÉRAVEL}

As circunstâncias teóricas e práticas que serão estudadas a seguir exploram as dificuldades de se delimitar a liberdade de vontade na infância e adolescência. Dizer em que termos e de que modo uma pessoa em desenvolvimento pode decidir aspectos importantes de sua vida é em si um problema complexo. No entanto, quando se trata da vida sexual, a questão acresce muitas variáveis e ganha em relevância, desafiando muitos questionamentos sociais.

Algo que se impõe de imediato é saber qual o papel do direito, esclarecendo, por exemplo, os critérios que a lei deve adotar para proteger a menoridade. $\mathrm{O}$ consentimento para o sexo na adolescência necessita de parâmetros claros, sob pena de promover ações de desproteção quando o desejo é de fato acolher pessoas em vulnerabilidade. Ademais, a liberdade de consentir no ato sexual tem consequências jurídicas importantes, afastando ou confirmando a consumação do crime de estupro e definindo, por outro lado, um importante marco para o início da idade adulta.

Mas a autonomia não representa apenas uma espécie de janela que descortina os meios aptos a delimitar a Justiça da Infância e Adolescência e sua capacidade de realizar direitos. Ela também constitui um elemento que coloca em evidência os fundamentos da jurisdição. É dizer, sendo o adolescente e sua família livres para decidir sobre a prática do sexo, autorizando ou não as relações íntimas, é o princípio da estrita legalidade que deve inspirar a interpretação da norma jurídica e a própria atuação do Estado. Do contrário, admitindo-se a tutela estatal do adolescente e de seus familiares, retirando-lhes com isso o poder de consentir o ato sexual, tem-se a precedência do princípio da proteção integral, já que pressupõe a existência de risco e de vulnerabilidade em determinada idade. Daí a importância de se problematizar o tema do consentimento, um pontochave na compreensão dos fins da Justiça especial, principalmente a partir de circunstâncias polêmicas e com teses já sedimentadas, seja na doutrina jurídica seja no imaginário coletivo. Nos próximos tópicos serão discutidas três circunstâncias, de modo a evidenciar o embate entre proteção e legalidade.

\subsection{Autonomia para o sexo}

A primeira situação hipotética indaga acerca do critério que deve regular a liberdade sexual na infância e adolescência, se de caráter estritamente biológico, a exemplo do marco etário, ou se deve contemplar nuances múltiplas, como os fatores biológicos, psicológicos, sociais e culturais. Mais especificamente, o problema questiona se o fator idade é suficiente para normatizar o consentimento ou se há necessidade de agregar outros aspectos que são variáveis em cada indivíduo, a exemplo da maturidade psicológica, do grau de instrução, do ambiente cultural, dos valores familiares, do comportamento social e da própria história de vida.

As soluções são conflitantes entre si. O critério biológico torna a consumação do crime de estupro de vulnerável uma questão objetiva, analisando apenas a idade da pessoa. $\mathrm{O}$ critério biológico-social, contudo, admite uma ponderação subjetiva do julgador, que deve avaliar numa determinada faixa etária o grau de desenvolvimento da pessoa. No primeiro, uma análise de subsunção é suficiente (o agente fez sexo com um menor de 14 anos?); no segundo, uma análise de razoabilidade se impõe caso a caso (o vulnerável deve ser protegido e tutelado pelo Estado ou por sua idade e desenvoltura social deve ser tratado imparcialmente como se adulto fosse?).

A escolha brasileira é decididamente pelo marco etário. A redação do artigo 217-A, CP, teve como objetivo afastar qualquer inferência acerca da vida da criança e do adolescente, em especial sua história de vida, seu envolvimento em situações ilícitas, a quebra dos vínculos familiares etc. O pressuposto é a proteção absoluta aos menores de 14 anos, aplicando-se, por 
conseguinte, a presunção absoluta de violência na hipótese de qualquer evento de natureza sexual5. Enfim, haverá estupro de vulnerável mesmo que a pessoa abaixo dessa idade seja integrante de uma rede de prostituição6.

No entanto, o esforço de flexibilizar o parâmetro é tão significativo que em 2017 o Superior Tribunal de Justiça (STJ) precisou editar a Súmula 593, determinando que "o crime de estupro de vulnerável se configura com a conjunção carnal ou prática de ato libidinoso com menor de 14 anos, sendo irrelevante eventual consentimento da vítima para a prática do ato, sua experiência sexual anterior ou existência de relacionamento amoroso com o agente" (BRASIL, STJ, DJe 06/11/2017). Deve-se perguntar o motivo de tanto esforço da comunidade jurídica em mobilizar uma Corte Superior, ao ponto de se tornar necessária a edição de uma súmula para esclarecer o sentido de um preceito legal cujo texto já é evidente por si mesmo.

O que anima a tensão no seio do tipo penal em estudo é o conflito hermenêutico. A defesa de que a presunção absoluta de violência deve ser afastada em determinadas situações na verdade sustenta a ideia de que a decisão deve repousar antes num juízo de razoabilidade caso a caso do que no juízo de legalidade estrita (garantismo formal). A crítica é de que o rigor da lei se baseia num positivismo formalista, vedando o cotejo da situação concreta com parâmetros normativos materiais e de cariz constitucional. A objetividade do tipo penal é, em termos mais precisos, indiferente ao pós-positivismo, cujo modelo de raciocínio projeta uma interpretação mais aberta, evitando subjugar a decisão judicial apenas à lei para também situá-la no plano dos princípios que erigem a ordem jurídica e adotando o que Bonavides (2013, p. 141-142) nomeia de método pluridimensional7. Tal postura vinculada exclusivamente à legalidade resultaria em injustiças para todas as partes interessadas.

Necessário, portanto, verificar o valor da tese hermenêutica pós-positivista de que a presunção absoluta de violência prevista para o artigo 217-A, CP, é injusta tanto para o réu quanto para a vítima. $\mathrm{O}$ argumento é falacioso ou é válido? Para tal, propõe-se a seguir a análise de mais duas situações hipotéticas em torno do estupro de vulnerável, com o fim de tornar mais clara a problemática.

\subsection{Família e tutela da liberdade sexual}

A segunda circunstância fática cinge-se à indagação acerca da existência de alguma circunstância na qual o critério biológico aplicado ao crime de estupro de vulnerável implica violação aos princípios constitucionais da infância e adolescência (prioridade absoluta, proteção integral e melhor interesse). Em outras palavras, se há meios de uma cláusula de proteção, aqui consubstanciada na objetividade do fator etário, representar, quando compreendida em sua estrita legalidade (positivismo formal), uma ofensa constitucional.

Antes de responder à indagação, vale lembrar que a presunção absoluta de violência para o sexo praticado com menor de 14 anos foi uma inovação de proteção da Lei n. 12.015/2009. O objetivo foi banir da jurisprudência brasileira os juízos negativos impostos às vítimas, qualificadas com frequência como crianças libertinas e provocadoras ou compreendidas simplesmente como

\footnotetext{
5 Até então prevalecia a presunção de violência do artigo 224, alínea "a", do Código Penal Brasileiro, contudo sem uma posição doutrinária e jurisprudencial pacífica quanto à qualidade da presunção, se absoluta ou relativa.

6 O propósito foi sempre o de impedir o emprego de juízos negativos de valor em face de crianças e adolescentes, recurso argumentativo usual nas cortes brasileiras para inocentar réus, taxando as vítimas de pervertidas, abandonadas e infratoras.

7 "O novo método é pluridimensional: abre-se aos valores, aos fins, às razões históricas, aos interesses, a tudo enfim que possa ser conteúdo e pressuposto da norma. O sistema constitucional já não é tão somente o sistema da Constituição normativa, mas está acrescido de todo aquele complexo de forças, relações e valores, que o positivismo formalista deliberadamente excluía ou ignorava e cuja totalidade, na medida em que tem uma eficácia fundamental, de maneira a moldar e ativar instituições básicas, compõe a ordem material da constituição, formando um núcleo ou círculo mais largo e compreensivo, excepcionalmente rico de conteúdo."
}

Revista de Direito Brasileira | Florianópolis, SC | v. 27 | n. 10 | p.162-177 | Set./Dez. 2020 
pessoas pervertidas pela vida de miséria e infortúnio8. Assim, a análise social de moralidade do ofendido (elemento alheio ao Direito) já não pode constituir um fundamento legítimo de defesa em razão de sua abordagem discriminatória, tendo sido vedado pela mudança legislativa em destaque.

Mas, o fato é que qualificações negativas convivem, contraditoriamente, com outras de caráter positivo. Do sistema lógico que produz um juízo negativo, qual seja, o raciocínio acerca da convivência social do indivíduo, surgem também juízos positivos. Expurgando o próprio olhar coletivo sobre a pessoa, todas as perspectivas são simultaneamente afastadas, boas ou más. É o que ocorre com a estrita legalidade, que banindo a análise das interações do indivíduo em sociedade impede qualquer ponderação de valores ou princípios, restringindo sobremaneira o espaço de atuação da jurisdição.

Nesse circuito restrito ao normativo e excludente de fontes pluridimensionais, a depender da situação concreta, réu e vítima podem ter interesses contrariados em prol da realização do Estado Penal. Um exemplo prático é o casal formado por um rapaz de 19 anos e uma menina de 13 anos. Se desta relação nasce um filho, tem-se uma família. Se há determinação de ambos viverem juntos, tem-se um laço afetivo com responsabilidades parentais definidas. Nada obstante isso, há crime. Atendidos os rigores formais e materiais do devido processo legal, concluída a ação penal, cabe a execução da pena. Os atores do conflito se tornam instrumentos do ideal carcerário sem que nada possa ser feito.

Então a resposta aos questionamentos supra é positiva. É, sim, possível haver violação a preceitos infantis ao se aplicar a estrita legalidade mesmo quando se almeja realizar uma cláusula de proteção, como na hipótese da presunção absoluta de violência do crime de estupro de vulnerável9. Afinal, é de se questionar como é possível que a formação de uma família e o nascimento de uma criança, com laços afetivos reais, possam fundamentar uma condenação criminal em detrimento do próprio vínculo familiar, separando-se uma família seja separada pelo cárcere. 10

8 Relata Abreu (2015, p. 289): “'Menina perdida' foi expressão utilizada pelo advogado de José Maria dos Santos, acusado, em 1904, no Rio de Janeiro de ter deflorado Olívia Silva Lisboa, de 15 anos. Olívia estaria nesta irremediável condição, apesar da idade, não apenas por ter perdido a virgindade, mas, segundo o advogado, pelo abandono em que se encontrava - "sem mãe" -, e com um pai que a "abandonara aos instintos perversos de que geralmente é dotada a mulher sem educação'. A narrativa espelha o olhar geral da educação infantil que Priore (2015, p. 105) revela: "Sábio conselho num país onde, há quinhentos anos, a formação social da criança passa mais pela violência explícita ou implícita do que pelo livro, pelo aprendizado e pela educação. Triste realidade num Brasil, onde a formação moral e intelectual, bem como os códigos de sociabilidade, raramente aproximam as crianças de conceitos como civilidade e cidadania".

9 Interessante conclusão encontraram Plachi, Branco e Mendes ao estudar a postura ativista do Supremo Tribunal Federal no julgamento do HC 122.072/2014, posto que a aplicação do princípio da presunção de inocência é compreendida, no caso concreto, como solução contrária à lei, ainda que favorável ao adolescente infrator: "Na decisão analisada, constata-se a presença desse traço, uma vez que o Supremo Tribunal Federal afastou a incidência da lei n. 8.069/90 e aplicou diretamente o princípio constitucional da Presunção de Inocência insculpido no art. $5^{\circ}$. LVII, CF, inovando, inclusive, a jurisprudência dos Tribunais Superiores, as quais, tradicionalmente, não aplicam o Princípio da Não Culpabilidade a adolescentes infratores sob a justificativa de que a determinação de internação encontra respaldo na legislação protecionista; o sistema recursal previsto no ECA é pautado no Código de Processo Civil e que não se considera a sentença de internação como pena, mas mecanismo de proteção ao adolescente e à sociedade" (p. 197, 2016).

10 Daí a pertinente observação de Melo (2010, p. 53-54) segundo a qual a Lei n. 12.015/2009 funda-se no modelo de proteção, mas despreza a promoção da autonomia e da liberdade do adolescente: "Em discussão está a tendência prevalecente no modelo de proteção e na prática habitual da sociedade de negar a possibilidade de exercício de direitos ou de remover as crianças das situações que são reputadas perigosas a elas ou nas quais suas necessidades não possam ser satisfeitas ou atendidas. Pelo contrário, o desafio deveria ser mudar as situações mesmas ou promover meios de satisfazer as necessidades delas e, sobretudo atender seus interesses (VERHELLEN, 2000, p. 25). Esse é o desafio de mudança de paradigma da passagem dos direitos de proteção, de bem-estar, aos direitos às liberdades e à participação, com o reconhecimento de competência para o exercício de direitos". 
A única solução possível é legalmente vedada. Não é possível fazer discriminação positiva11, adotando a ponderação de valores e um estudo psicossocial do caso - uma mera crítica sociológica seria suficiente para afastar a condenação criminal, autorizando inferir que a proteção penal seria mais danosa que o reconhecimento da autonomia sexual da adolescente 12. Um juízo de razoabilidade resultaria igualmente justo, permitindo concluir que o princípio da proteção integral de crianças e adolescentes deve guardar harmonia com os princípios da proteção familiar e da responsabilidade parental (art. 226, CF). Por fim, poder-se-ia alegar o melhor interesse do filho do casal para justificar a absolvição, uma vez que a pena atingiria todo o núcleo familiar, transcendendo a esfera jurídica do réu.

Mas, por óbvio, adotar soluções desse jaez implicaria uma postura ativista. A jurisdição infanto-juvenil estaria sendo disposta ao senso coletivo de justiça em detrimento da letra fria da lei.

\subsection{Abusos no consentimento}

Uma terceira situação hipotética contempla resultados diferentes e parte de questionamento inverso ao item anterior, ou seja, se é possível imaginar alguma circunstância na qual a hermenêutica constitucional aplicada ao crime de estupro de vulnerável implica violação aos princípios constitucionais da infância e adolescência (prioridade absoluta, proteção integral e melhor interesse). De forma mais precisa, indaga-se se há meios de uma cláusula de proteção representar uma ofensa à $\mathrm{CF}$, quando compreendida numa interpretação que considere as condições sociais da ação humana e suas necessidades de socialização e de garantia de direitos de liberdade e sociais (método pluridimensional do pós-positivismo).

Casos concretos de abuso no consentimento para o sexo podem esclarecer essa hipótese. Tome-se o exemplo da adolescente de 16 anos que vai para uma festa de um rico empresário, de 40 anos, que está recebendo convidados numa boate para comemorar seu aniversário. Chegando ao evento, dada a ampla oferta de bebidas, ela começa a ingerir álcool. $\mathrm{O}$ aniversariante percebe $\mathrm{o}$ estado da jovem, abordando-a para o namoro. O consumo de álcool persiste e o casal se dirige ao banheiro para ter relações sexuais. A relação foi consentida pela adolescente, que em seguida continua a beber e se embriaga a ponto de passar mal, vomitando repetidas vezes. Ela pede para ir para casa, porém o empresário a leva para sua própria residência. Ela se recusa a entrar, mas é conduzida ao seu interior, oportunidade na qual ocorrem novas relações sexuais. No dia seguinte, o casal se comporta como namorados, o empresário oferece um café da manhã e depois deixa a adolescente em casa. A jovem não se recorda bem de todos os fatos registrados na residência do empresário, em razão da embriaguez, mas sabe que fez novamente sexo no local e resolve, uma semana após o acontecido e depois de revelar a situação a seus pais, denunciá-lo por estupro de vulnerável (artigo 217-A, $\S 1^{\circ}, \mathrm{CP}$ ). A narrativa revela uma dinâmica fática escalonada, com um

\footnotetext{
11 Seria o caso, portanto, de quebrar a rigidez normativa, como sugere Souza (2010, p. 97): "Vale dizer que as crianças, os adolescentes e os jovens devem se integrar em um diálogo permanente com os adultos e construírem estratégias de reflexão crítica sobre suas experiências em um mundo sem garantias, criando modo de dialogar com as leis, sem necessariamente se submeterem às regras de um jogo definido de antemão, mas como sujeitos que podem interferir nesse jogo, propondo novas regras e definindo a cada momento outros caminhos possíveis para o jogo e para a vida". 12 Nem mesmo é devido ouvir a adolescente vítima e considerar sua palavra, ainda que a tutela jurisdicional da infância se caracterize pela interdisciplinaridade, participação e oitiva obrigatória da criança, como lecionam Souza Neto e Amaral (2013, p. 79-80): "Os modelos de constatação de prova a serem obedecidos nas demandas infantojuvenis aparecem no Estatuto da Criança e do Adolescente como verdadeiros princípios gerais do direito a serem observados em toda sorte de demanda, em especial nas tutelas de urgência. A intervenção de profissionais de saberes afins ao direito impõe-se, sendo reservado à equipe técnica interdisciplinar importante papel, na medida em que aporta elementos e questões determinantes para a construção de uma decisão justa e adequada. A efetiva participação e a obrigatória oitiva da criança e do adolescente nas demandas em que sua própria sorte estará em jogo também se impõem".
} 
primeiro momento em que há o consentimento para o sexo e um segundo no qual o agente abusa da manifestação de vontade inicial da vítima, o que leva ao ato sexual não consentido.

Esse contexto dúbio de consentimento e não-consentimento permite, em eventual ação penal, uma sentença de absolvição com fundamentos razoáveis: a) os direitos de liberdade devem ser protegidos mesmo na adolescência, concluindo-se que: a.1) a adolescente se dirigiu para a festa e ingeriu álcool por decisão própria; a.2) uma pessoa com a idade de 16 anos tem liberdade sexual, devendo respeitar sua autonomia; a.3) uma pessoa com a idade de 16 anos tem liberdade para participar de festas, devendo respeitar sua iniciativa social; b) os direitos de cidadania da adolescente devem ser protegidos, o que impõe tratá-la como sujeito de direitos, de modo que: b.1) o depoimento da vítima deve ser analisado objetivamente e sem paternalismo, observando todas as contradições do relato; b,2) a evolução do consentimento ao não-consentimento deixa margens para dúvidas, tendo a vítima se comportado como namorada do suposto ofensor no dia seguinte ao ocorrido; b.3) a demora em fazer a denúncia igualmente levanta suspeitas, considerando ainda que a notícia-crime foi apresentada somente após a revelação do fato aos pais; b.4) o dissenso pode ter sido posterior ao ato sexual, e não concomitante; c) a proteção integral da adolescente implica proteger o protagonismo individual e a condição de pessoa responsável por seus próprios atos, o que leva a entender que: c.1) a culpa da vítima em se colocar em estado de embriaguez isenta de culpa o agressor de práticas sexuais abusivas, não restando claro o dolo do agente de se aproveitar do estado da ofendida; c.2) o agente não agiu para embriagar a vítima, sendo ela a única responsável por sua embriaguez; c.3) in dubio pro reo.

A decisão judicial nos termos apresentados acima contraria a tese da "adolescente vítima" e adota argumentos de proteção da "adolescente livre e com autonomia" para desautorizar o seu próprio depoimento, numa postura abertamente ativista. Primeiro porque foca a interpretação numa discussão ideológica estranha ao direito13, qual seja o protagonismo juvenil em detrimento do paternalismo, expressando um juízo de valor acerca da ofendida, compreendida como uma adolescente independente e que age por conta própria. Segundo porque planeja, ao absolver o réu, expurgar teorias moralistas e proteger os direitos à liberdade sexual e à vida social da adolescente. Terceiro, e por último, porque a sentença centra-se na análise da condição social da adolescência (protagonismo) e abstém-se de aplicar a estrita legalidade, com a qual o resultado seria a condenação, uma vez que as duas elementares do tipo penal não foram contestadas, a prática de sexo e o estado de vulnerabilidade da vítima, que não podia oferecer resistência em razão de estar embriagada - sob a perspectiva da lei, não há como deixar de reconhecer a subsunção do fato à norma penal.

Ora, os argumentos da sentença são razoáveis, mas o resultado do julgamento, não. A decisão desenvolve um discurso que promove uma inversão de valores, na medida que desqualifica a palavra da adolescente com fundamento na proteção da adolescência. A lógica é dissociar o individual do coletivo, desproteger a posição pessoal da jovem, consubstanciada na denúncia do crime, para proteger sua posição social, caracterizada no protagonismo juvenil. Na prática, o raciocínio extrai da adolescência o aspecto da vulnerabilidade para imputá-lo ao adulto, esquecendo que a presunção de culpa da vítima é incompatível com o dever de proteção prioritário e integral à infância e adolescência exigido pelo artigo 227 da $\mathrm{CF}$ e pelos artigos $4^{\circ}, 5^{\circ}, 6^{\circ}, 15$ e 18 da Lei n. 8.069/1990.

No caso, o argumento adequado seria afirmar que o réu, experiente pela idade e pela profissão, assumiu deveres de proteção ao receber uma adolescente em sua festa. Com isso, tinha a obrigação de zelar por sua integridade, impedir que ingerisse bebida alcoólica e cuidar para que deixasse o local na companhia de pessoas responsáveis. Se assim não agiu é porque havia o dolo

13 Expressa uma racionalidade substancial e distinta da racionalidade lógico-formal da classificação de Max Weber, como leciona Trubek (2007, p. 163): “A racionalidade substancial, por outro lado, é, de certo modo, governada por regras - por isso é chamada de 'racional' - mas tais regras são princípios de um corpo de pensamento externo ao direito, tal como uma religião, uma filosofia ética ou uma ideologia". 
para ações ilícitas14. Era devido ao magistrado ponderar, ainda, que o sentimento de culpa impede que a vítima de estupro tenha a representação apropriada de sua condição, estando subjugada em suas emoções e também em sua capacidade cognitiva, porquanto inserida num contexto de falsidade e manipulação15. E, mais, que o depoimento prestado sob a proteção familiar é o mais verossímil, devendo privilegiar a interpretação que a ofendida tem dos fatos após estar devidamente orientada pelos pais, expurgando as dúvidas acerca de sua fala16. Por fim, se preferisse, poderia o magistrado simplesmente se limitar ao juízo de subsunção, evitando inclusive esses últimos argumentos, porquanto também capazes de configurar o ativismo de uma interpretação engajada na defesa dos direitos de crianças e adolescentes.

Então, é correto responder positivamente à indagação feita no início do presente tópico. A interpretação que se afasta da estrita legalidade em prol de uma hermenêutica constitucional de proteção de direitos de liberdade e direitos sociais pode implicar uma violação aos princípios constitucionais da infância e adolescência17. O exemplo do abuso no consentimento para o sexo demonstra isso. O resultado é diametralmente oposto à situação hipotética examinada no item anterior, na qual foi a aplicação fria da lei a responsável por soluções iníquas.

\subsection{Avaliação dos resultados}

O estudo do crime de estupro de vulnerável teve como fim submeter ao exame de falseabilidade as seguintes teses: a) a Justiça da Infância e Adolescência é essencialmente ativista em razão de sua natureza baseada na proteção; b) em cada caso concreto devem ser ponderados os valores contrapostos da proteção e da imparcialidade, não sendo devido almejar uma jurisdição objetiva e uma atuação técnico-formal.

Assim, a análise das situações hipotéticas que envolvem a presunção absoluta de violência prevista para o artigo 217-A, CP, e dos casos concretos que elas projetam, como exposto acima, oferece algumas conclusões provisórias.

Primeiro, comprovou-se que o ativismo é de fato uma realidade no cotidiano da Justiça da Infância e Adolescência, tendo sido constatado, com a identificação de argumentos usuais e de fácil legitimação, um forte apelo ao discurso de proteção e ao emprego de elementos extrajurídicos. Trata-se de uma prática sem respaldo legal, já que o paradigma da proteção integral antes insere a infância no plano da legalidade do que a enlaça em enredos ideológicos ou em aspirações moralistas.

14 Nesse sentido, o artigo 18 do ECA dispõe que "é dever de todos velar pela dignidade da criança e do adolescente, pondo-os a salvo de qualquer tratamento desumano, violento, aterrorizante, vexatório ou constrangedor". Tem-se aqui uma cláusula geral de proteção, que abrange crianças e adolescentes e que impede aplicar a ideia de presunção de culpa na hipótese de embriaguez voluntária.

$15 \mathrm{O}$ artigo 15 do ECA dispõe que "a criança e o adolescente têm direito à liberdade, ao respeito e à dignidade como pessoas humanas em processo de desenvolvimento e como sujeitos de direitos civis, humanos e sociais garantidos na Constituição e nas leis." Em outras palavras, liberdade, respeito e dignidade são preceitos que coordenam em conjunto a interpretação acerca dos fatos de relevância jurídica para crianças e adolescentes, não sendo devido exegeses pontuais e isoladas destes valores.

16 A Lei n. 13.431, de 4 de abril de 2017, conhecida como Lei da Escuta, estabelece no artigo $5^{\circ}$ que a aplicação legal tem como base, entre outros, os direitos e garantias fundamentais da criança e do adolescente, em especial receber prioridade absoluta, ter considerada a condição peculiar de pessoa em desenvolvimento e ter acesso a tratamento digno e abrangente.

$17 \mathrm{O}$ ativismo permite soluções discricionárias que ofendem a ordem jurídica e a democracia, como ressalta Saboia (2018, p. 343): “A relativização da vontade do constituinte permite ao intérprete da lei distanciar-se daquilo que é jurídico para, valendo-se de sua discricionariedade, criar interpretações que melhor reflitam a sua própria visão de mundo e de justiça. Isso faz a sociedade começar a questionar acerca dos limites entre interpretação e criação judicial do Direito e da legitimidade democrática, analisando o perigo que decisões norteadas pela vontade (e, portanto, alheias ao Direito) representam para a democracia".

Revista de Direito Brasileira | Florianópolis, SC | v. 27 | n. 10 | p.162-177 | Set./Dez. 2020 
Constatou-se em seguida que, apesar de o ativismo ter fundamentos de proteção, não é possível afirmar que esse discurso gere resultados práticos de proteção, uma vez que tanto a legalidade estrita e formal quanto as razões ativistas alcançam soluções que ora promovem, ora anulam direitos fundamentais. Talvez seja esse o achado mais vigoroso do debate sobre o consentimento para o sexo nos crimes de estupro de vulnerável, principalmente porque desmistifica a ideia de que um discurso de proteção, ainda que utilize argumentos razoáveis, necessariamente promove e realiza os direitos da criança e do adolescente. Portanto, o ativismo na jurisdição especializada da infância e adolescência floresce no terreno fértil de uma argumentação vazia e dissociada do texto legal e da própria realidade. Afinal, não é bastante se inspirar na proteção da criança, é preciso que a Justiça coordene a atitude de proteger com as determinações da lei. Os direitos fundamentais dependem dessa estratégia para serem eficazes.

Sob a perspectiva dessas duas primeiras conclusões, de pronto evidencia-se que as duas teses em exame não são verdadeiras. Não é devido falar em essencialidade ativista e também não há como referendar a análise casuística de cada caso concreto para definir os meios adequados para salvaguardar o infante. Assim, é possível avançar para uma terceira e última constatação.

Com efeito, observa-se por fim que a variação de resultados de proteção e desproteção, nada obstante o discurso de defesa e promoção de direitos fundamentais, revela que o problema do ativismo é antes de tudo uma questão hermenêutica - argumentos de proteção não são suficientes, já que sujeitos à subjetividade e à discricionariedade do julgador18. Ou seja, a possibilidade da Justiça da Infância e Adolescência caracterizar uma jurisdição técnica e garantista, mesmo que diferenciada em razão de direitos que são prioritários e integrais, depende dos métodos de interpretação. É a hermenêutica que pode garantir à jurisdição especial um caráter formal e ao mesmo tempo capaz de promover os valores constantes nos princípios da prioridade absoluta, proteção integral e melhor interesse (resolvendo, assim, o dilema entre proteção e imparcialidade, item b, supra - qual item b?).

\section{O ATIVISMO E A PERSPECTIVA GARANTISTA DO DIREITO}

Admitir que a questão é de interpretação significa dizer que o ativismo não é uma condição ontológica da Justiça da Infância e Adolescência. Igualmente, implica afirmar que o magistrado da Infância e Adolescência não deve decidir sob a inspiração da pauta moral que a figura do "bom pai" projeta, agindo de forma discricionária na defesa de uma comunidade familiar abstratamente considerada. Do contrário, a atividade jurisdicional deve estar confiada à lei e à racionalidade hermenêutica19.

Então, o que surge de relevo é estabelecer as diretrizes de interpretação20. Ou seja, necessário definir a lógica que melhor coordene a proteção da legalidade com o dever de proteção dos direitos de crianças e adolescentes imputados à jurisdição especial pelos princípios constitucionais.

Na visão de Ferrajoli (2006, p. 808), é impróprio falar em dicotomia entre lei e princípios constitucionais, já que ambas as espécies normativas se integram num único processo exegético de análise da vigência e da validade da norma jurídica21. Para ser aplicada, a lei precisa ter vigência

18 Dessa forma, qualquer argumento pode ser empregado para legitimar a proteção, ainda que na prática promova a violação de direitos.

19 Nesses termos, conferir Streck e Motta (2012, p. 10): "Daí a constante pergunta: de que modo poderíamos/deveríamos conter/controlar essa vontade de poder? Mas essa, fundamentalmente, é a nossa pergunta. E por quê? Porque falamos do lugar da hermenêutica. E porque desconfiamos da sapiência desse sujeito protagonista". 20 Trata-se, assim, da defesa da coerência interna do direito, como atestam Saboia e Santiago (2018, p. 69): “Os juízes devem seguir critérios seguros na atividade interpretativa, partindo da noção de integridade e coerência do Direito e não das convicções pessoais e/ou políticas do aplicador".

21 "Para que a previsão de um fato como crime por uma lei seja suficiente, de modo a fazê-lo considerar como tal também pelo juiz, ocorre, em um Estado de direito, que a lei seja, além de vigente, também válida, isto é, de acordo

Revista de Direito Brasileira | Florianópolis, SC | v. 27 | n. 10 | p.162-177 | Set./Dez. 2020 
formal, porquanto instituída segundo o devido processo legislativo para regular determinado fato, e validade substancial, uma vez que conforme aos valores constitucionais correlatos e ao empreendimento de conformação dos direitos fundamentais. Por conseguinte, a regra tem em si duas instâncias de positivação, uma que lhe garante existência e outra que lhe empresta aplicabilidade, raciocínio que revela uma legitimidade interna (porquanto imanente ao próprio direito positivo): a lei infraconstitucional e os princípios constitucionais são normas positivadas que se integram, nos planos de vigência e validade, como um único momento normativo22.

O Estado de Direito, na perspectiva do garantismo ferrajoliano, estabelece obrigações claras ao magistrado, que precisa motivar a decisão e observar, na análise do caso concreto, a correspondência desta às normas superiores, justificando assim sua aplicação. Isso empresta ao ato jurisdicional meios diversos de racionalização, seja vinculando o julgamento à correta motivação da sentença, o que torna viável submetê-la ao juízo de verificação23, seja conformando a lei, as atividades processuais e os resultados deste aos ditames da Constituição24. O conceito de estrita legalidade abrange, desse modo, uma série de garantias formais e materiais, que interagem para proteger o cidadão de decisões arbitrárias do Estado. Tem um viés substancial na medida que contém em si a noção de aplicabilidade dos princípios constitucionais e de eficácia dos direitos fundamentais.

A arquitetura desse pensamento autoriza inferir importantes orientações hermenêuticas, dentre as quais merecem destaque aquelas de maior pertinência ao presente estudo: a) a regra infraconstitucional traz em si um princípio constitucional, integração que se torna evidente a partir da implicação lógica entre vigência e validade (toda regra contém um princípio que a institui25); b) o dever de motivar a sentença exige o dever de coerência e, via de consequência, a obrigação de

com suas normas superiores, seja do ponto de vista formal quanto sob aquele substancial. Apenas uma lei (por ele considerada) válida comporta a obrigação ao juiz de aplicá-la, isto é, de qualificar e punir como delito o fato por ela previsto. Disto deriva que um fato deve ser considerado um crime se, e somente se, tem como base uma lei vigente e válida, ou ainda se concorrem todas as garantias penais e processuais: que é a definição teórica e legal - isto é, descritiva, entre um Estado de direito, e não apenas prescritiva - da noção válida de 'crime' formulada no parágrafo 28.3".

22 "É ao contrário a tese kelseniana da identidade entre vigência e validade que é desvestida de capacidade explicativa com relação às hodiernas democracias constitucionais, nas quais a previsão normativa e a realidade concretizada pelas jurisdições de constitucionalidade atestam quotidianamente a existência de normas legais vigentes porém inválidas" (FERRAJOLI, 2012, p. 41-42).

23 "Verificabilidade e verificação das motivações, como mostrei na primeira parte, são por outro lado as condições constitutivas da estrita legalidade e da estrita submissão à jurisdição das decisões judiciárias. E como tais valem para garantir aquele específico direito fundamental que interessa ao direito penal e que é a imunidade do cidadão inocente a punições arbitrárias. Disso resulta que o vínculo da verdade processual é também a principal fonte de legitimação externa, ético-política, ou substancial do Poder Judiciário, que, diversamente de qualquer outro poder público, não admite uma legitimação de tipo representativo ou consensual, mas apenas uma legitimação do tipo racional e legal, adequada ao caráter cognitivo dos fatos e recognitivo da sua qualificação jurídica, que é indispensável à motivação dos atos jurisdicionais" (FERRAJOLI, 2006, p. 500-501).

24 Lembra Rosa (2003, p. 89): "Com efeito, as possibilidades hermenêuticas do garantismo dependem de um deslocamento a ser efetuado no campo da linguagem, suplantando-se as velhas maneiras de significar desde dentro da jaula do senso comum teórico. É preciso assumir a consciência da autonomia do ator jurídico no processo de atribuição de sentido".

25 "A hermenêutica, a partir do que venho denominando de uma Crítica Hermenêutica do Direito ou Nova Crítica do Direito, que introduz na relação texto-norma a diferença ontológica (ontologische Differentz), locus do mundo prático que é afastado pelas diversas teorias discursivo-procedurais, procura ultrapassar igualmente o dualismo "regraprincípio", evitando-se, assim, a repristinação da subsunção e da dedução para os assim denominados "casos simples" (lembremos a todo instante que, para as teorias argumentativas, os casos simples são resolvidos dedutivamente!)" (STRECK, 2008, p. 396). De forma ainda mais precisa, conferir Streck e Motta: "Essas premissas fazem com que se compreenda melhor a noção proposta, de que cada regra tem um princípio que a institui. Claro: se o Direito deve ser coerentemente produzido, e se essa coerência é principiológica, evidentemente que toda a regra (como manifestação do Direito) deve encontrar justificativa no emaranhado de princípios que o integra. A regra não subsiste sozinha, não retira validade de si própria. Ela deve ter algum sentido coerente com a integridade do Direito. A esse sentido, que não é prévio, que não é fixo, que não pode ser aferido proceduralmente, dá-se o nome de princípio" (2012, p. 4).

Revista de Direito Brasileira | Florianópolis, SC | v. 27 | n. 10 | p.162-177 | Set./Dez. 2020 
garantir verificabilidade à decisão; c) a atividade jurisdicional deve guardar harmonia com os preceitos constitucionais, contudo não é devido ao magistrado a escolha aleatória de quaisquer princípios, eis que a conformação material se sujeita aos princípios indicados pela própria regra em aplicação no caso concreto26.

Mas, deve-se questionar se as diretrizes assinaladas são suficientes para decidir a dicotomia proteção-imparcialidade na Justiça da Infância e Adolescência e demonstrar a perspectiva técnica que essa jurisdição tem em potência, revelando a impropriedade e a desnecessidade de afirmar um suposto ativismo ontológico, que seria natural à jurisdição especializada.

O contexto discutido acima acerca das situações hipotéticas envolvendo o crime de estupro de vulnerável oferece oportunidades para testar a eficiência desses comandos. Ora, sendo capazes de solucionar as aporias identificadas nas circunstâncias fáticas, então será possível asseverar que a estrita legalidade, nos termos do garantismo proposto por Ferrajoli, apresenta os instrumentos necessários para uma interpretação comprometida ao mesmo tempo com a lei e com os valores constitucionais. Ademais, será válido afirmar que na prática não existe a dicotomia proteção-imparcialidade, porquanto momentos de um só ato interpretativo (assim como vigência e validade se integram numa instância única de compreensão), no qual a neutralidade do juiz se identifica com a promoção de direitos. Por fim, será devido situar a Justiça da Infância e Adolescência num ambiente de racionalização hermenêutica, refutando não apenas o ativismo como também as receitas paternalistas e moralistas que marcam a história dessa jurisdição especial.

Foram apresentadas três situações hipotéticas: autonomia para o sexo, família e tutela da liberdade sexual e abusos no consentimento. Ao confrontá-las com a tese da dicotomia entre o dever de proteção dos direitos da infância e o dever de imparcialidade, chegou-se a um conjunto de dificuldades lógicas que lançam dúvidas no paradigma de justiça.

$\mathrm{Na}$ questão da autonomia para o sexo, por exemplo, questionou-se o valor da legalidade em si, considerando que a presunção absoluta de violência do crime de estupro de vulnerável se baseia num positivismo formalista, proibindo o cotejo da situação concreta com parâmetros normativos constitucionais e ameaçando direitos fundamentais do réu e da vítima.

Tal afirmação foi demonstrada na análise das outras duas circunstâncias. No estudo da família e da tutela da liberdade sexual, observou-se o caso do jovem de 19 anos e da adolescente de 13 anos, genitores de uma criança e integrantes de uma família que vive a pressão da ação penal, considerando a incidência implacável da cláusula de presunção absoluta de violência. Na questão do abuso no consentimento, investigou-se a sentença com uma interpretação ativista e de proteção ao direito à liberdade sexual, levando à absolvição do réu. Assim, em ambos os relatos há ameaça a direitos fundamentais, ainda que um priorize a lei e o outro uma hermenêutica alinhada com o protagonismo juvenil.

Ocorre que os dois casos concretos podem ser solucionados pela estrita legalidade em sua perspectiva garantista, sem gerar as violações de direitos de liberdade suscitadas há pouco, produzindo, de igual forma, uma resposta adequada para a questão da presunção absoluta de violência (primeira situação hipotética).

Nesse sentido, a ação penal do jovem casal pode guiar-se para a absolvição mediante o seguinte raciocínio: a) o bem jurídico protegido no artigo 217-A, do Código Penal Brasileiro, é a dignidade sexual de crianças e adolescentes27; b) considera-se crime ter conjunção carnal ou

26 A integração entre regra e princípio, este último instituindo a primeira, de certo modo compõe uma solução ao problema da demasiada abstração que o reconhecimento da força normativa dos princípios impõe ao positivismo, como pontua Kaufmann (2009, p. 77-78): "Um dos muitos problemas que aqui surge é o de saber se os princípios gerais do direito não serão demasiado abstractos e pobres de conteúdo para que se possa chegar a concretas decisões jurídicas correctas apenas a partir deles".

27 O bem jurídico protegido é importante limite hermenêutico, como lecionam Oliveira e Santiago (2018, p. 47): "Desse modo, o grande risco à legalidade penal surge no momento em que a interpretação judicial estende o sentido e a abrangência do texto normativo, indo além da perspectiva de garantia individual e de contenção do poder punitivo. 
praticar ato libidinoso com menor de 14 anos, regra que exige a ofensa ao bem jurídico protegido (nullum crimen sine iniuria); c) a constituição de uma família pelo réu e pela suposta vítima, com a convivência afetiva perdurando desde a data dos fatos investigados, gerando um filho em comum, demonstra a inexistência de ofensa à dignidade sexual da adolescente vítima; d) o fato tem referência a uma norma que no caso concreto apresenta vigência, porém não goza de validade, por não se harmonizar com o princípio da ofensividade28, preceito referendado pela comunidade política29 e jurídica30; e) é de se reconhecer, na circunstância em análise, a autonomia da adolescente para decidir acerca de sua dignidade sexual, considerando a pretensão, ainda que precoce, de constituir e manter uma unidade familiar, o que desautoriza qualquer ilação quanto à ofensa ao bem jurídico.

Já a sentença referente ao abuso no consentimento pode desenvolver a seguinte lógica: a) a palavra da vítima de violência sexual deve ser interpretada no contexto dos fatos e em razão das demais provas juntadas ao processo, tendo em vista a necessidade de estabelecer a coerência do relato; b) não é devido valorar o depoimento da ofendida em prol de qualquer ideologia, mesmo que expresse conteúdo em defesa da adolescência; c) a fala da adolescente vítima de violência sexual deve ser protegida pelos aspectos legais que regulam a tomada do depoimento (Lei $\mathrm{n}$. 13.431, de 4 de abril de 2017), e não por ilações subjetivas do julgador; d) o fato de a vítima ter se colocado em perigo não diminui o valor probatório de seu depoimento nem elide o caráter ilícito da conduta do agressor; e) a dignidade sexual da adolescente deve ser compreendida no contexto da proteção constitucional assegurada à adolescência, integrando os princípios da prioridade absoluta, proteção integral e melhor interesse; f) no caso concreto, a incidência do artigo 217-A, $\mathrm{CP}$, é válida desde que seja possível apontar aspectos fáticos que consubstanciem uma ofensa ao preceito que confere materialidade ao tipo penal (dignidade sexual de crianças e adolescentes como expressão do princípio da dignidade humana).

Eis a solução técnica digna de uma jurisdição técnica31, o que dispensa qualificar como necessariamente ativista a Justiça da Infância e Adolescência.

\section{CONCLUSÃO}

Os resultados alcançados no presente estudo são limitados ao objeto de investigação e às situações analisadas no texto, sendo certo que não esgotam a complexidade do protagonismo judicial na área da infância e adolescência. Feita essa advertência, é de se concluir que:

a) A estrita legalidade, na concepção conferida pelo garantismo, oferece meios hermenêuticos aptos a conciliar a proteção da lei com a proteção dos direitos de crianças e adolescentes;

\footnotetext{
Ainda nesse contexto, cabe explicitar que o principal limite à interpretação judicial deve fixar-se no bem jurídico protegido pela norma, que, por sua vez, necessita ser precisamente identificado".

28 Conferir Ippolito (2011, p. 38): "Os princípios da ofensividade, da materialidade e da responsabilidade pessoal definem as condições necessárias para justificar as proibições penais, identificando os elementos constitutivos do delito no evento, na ação e na culpa. O princípio da ofensividade prescreve a delimitação do campo do proibível somente às ações nas quais o efeito consiste em um dano a terceiros".

29 Sobre o crime de bigamia, comenta Voltaire (2006, p. 64): "A sociedade convencionou secretamente não processar delitos dos quais ela se acostumou a rir".

30 Não é devido afastar a aplicação do princípio sem uma justificativa apta a tal, especialmente quando apresenta um comando que é compartilhado pelos sujeitos de instituições políticas (na falta de movimentos para legislar contrariamente ao princípio) e jurídicas (considerando a existência de julgados aplicando o princípio, a exemplo, dentre muitos, do acórdão BRASIL, STJ, DJe 08/04/2019).

31 Nada obstante a busca por um tecnicismo garantista no presente estudo, vale registrar a advertência de Costa quanto à utopia da segurança jurídica: "Por isso, em qualquer sistema processual concretamente considerado, sempre haverá o convívio simultâneo de elementos para a garantia das partes (funcionalizados à concretização do valor-mor da segurança) e elementos propulsores da iniciativa judicial (direcionados à realização do valor-mor de justiça) (2013, p. 185).
} 
b) O dever de proteção dos direitos de crianças e adolescentes não pode ser confiado ao ativismo judicial, porquanto sujeito a atitudes discricionárias, nas quais não há possibilidade de qualquer controle, sendo viável, inclusive, o contrassenso de fundamentar um ato de desproteção com base na ideia de proteção (a exemplo da hipótese do abuso no consentimento para o sexo);

c) Desqualificar o ativismo judicial como qualidade ontológica da Justiça da Infância e da Adolescência (característica natural decorrente da obrigação de proteger) não compreende uma crítica à especialização dessa jurisdição, antes reforça a necessidade de pesquisar, regular e promover boas práticas judiciais, em prol de modelos resolutivos, da adequação às demandas jurídicas próprias da infância e de uma justiça amiga da criança (a eficácia e a eficiência da justiça são corolários do princípio do devido processo legal).

\section{REFERÊNCIAS}

ABREU, Martha. Meninas perdidas. In: PRIORE, Mary Del (Organizadora). História das crianças no Brasil. $7^{\text {a }}$ ed. São Paulo: Contexto, 2015, p. 289-316.

AMARAL E SILVA, Antônio F. do. O estatuto, o novo direito da criança e do adolescente e a justiça da infância e da juventude. In: SIMONETTI, Cecília, BLECHER, Margaret, MENDEZ, Emilio García (compiladores). Do avesso ao direito: da situação irregular à proteção integral da infância e da adolescência na América Latina. São Paulo: Malheiros, 1994, p. 259-302.

BONAVIDES, Paulo. Curso de direito constitucional. $28^{\mathrm{a}}$ ed., atual. São Paulo: Malheiros Editores, 2013.

BRASIL. Constituição da República Federativa do Brasil, de 5 de outubro de 1988 (DOU de 5 out. 1988). Disponível em:

<http://www.planalto.gov.br/ccivil_03/constituicao/constituicao.htm>. Acesso em 14 dez. 2019.

BRASIL. Decreto-lei n. 2.848, de 7 de dezembro de 1940 (DOU de 31 dez. 1940). Código Penal. Disponível em: <http://www.planalto.gov.br/ccivil_03/decreto-lei/del2848compilado.htm>. Acesso em 14 dez. 2019.

BRASIL. Lei n. 8.069, de 13 de julho de 1990 (DOU de 16 jul. 1990 e retificado em 29 set. 1990). Dispõe sobre o Estatuto da Criança e do Adolescente e dá outras providências. Disponível em: <http://www.planalto.gov.br/ccivil_03/leis/18069.htm>. Acesso em 14 dez. 2019.

BRASIL. Lei n. 12.015, de 7 de agosto de 2009 (DOU de 10 ago. 2009). Altera o Título VI da Parte Especial do Decreto-Lei $\mathrm{n}^{\circ} 2.848$, de 7 de dezembro de 1940 - Código Penal, e o art. $1^{\circ}$ da Lei $\mathrm{n}^{\circ} 8.072$, de 25 de julho de 1990, que dispõe sobre os crimes hediondos, nos termos do inciso XLIII do art. $5^{\circ}$ da Constituição Federal e revoga a Lei ${ }^{0} 2.252$, de $1^{\circ}$ de julho de 1954 , que trata de corrupção de menores. Disponível em: < http://www.planalto.gov.br/ccivil_03/_Ato20072010/2009/Lei/L12015.htm>. Acesso em 14 dez. 2019.

BRASIL. Lei n. 13.431, de 4 abril de 2017 (DOU de 5 abr. 2017). Estabelece o sistema de garantia de direitos da criança e do adolescente vítima ou testemunha de violência e altera a Lei n. 8.069, de 13 de julho de 1990 (Estatuto da Criança e do Adolescente). Disponível em: <http://www.planalto.gov.br/ccivil_03/_Ato2015-2018/2017/Lei/L13431.htm>. Acesso em 14 dez. 2019. 
BRASIL. Superior Tribunal de Justiça. Agravo Regimental no Habeas Corpus 484.968/SP. Relator Ministro Antonio Saldanha Palheiro, Sexta Turma, julgado em 26/03/2019, DJe 08/04/2019. Disponível em:

$<$ http://www.stj.jus.br/SCON/jurisprudencia/toc.jsp?livre=PRINC\%CDPIO+DA+OFENSIVIDA DE+APLICABILIDADE\&b=ACOR\&thesaurus=JURIDICO\&p=true> . Acesso em 04 mai. 2019.

BRASIL. Superior Tribunal de Justiça. Súmula 593. Terceira Seção, julgado em 25/10/2017, DJe 06/11/2017. Disponível em:

<http://www.stj.jus.br/SCON/sumanot/toc.jsp?materia=\%27DIREITO\%20PENAL\%27.mat.\#TIT 27TEMA0>. Acesso em 18 abr. 2019.

COSTA, Eduardo José da Fonseca. Uma espetroscopia ideológica do debate entre garantismo e ativismo. In: DIDIER JÚNIOR, Fredie; NALINI, José Renato; RAMOS, Glauco Gumerato; LEVY, Wilson (coord.) Ativismo judicial e garantismo processual. Salvador: Jus Podivm, 2013, p. 171-186.

FERRAJOLI, Luigi. Direito e razão: teoria do garantismo penal. Trad. Ana Paulo Zomer Sica, Fauzi Hassan Choukr, Juarez Tavares e Luiz Flávio Gomes. $2^{a}$ ed. rev. e ampl.. São Paulo: RT, 2006.

FERRAJOLI, Luigi. Uma discussão sobre direito e democracia. Trad. Alexander Araújo de Souza. Rio de Janeiro: Lumen Juris, 2012.

IPPOLITO, Dario. O garantismo de Luigi Ferrajoli. Revista de Estudos Constitucionais, Hermenêutica e Teoria do Direito (RECHTD), São Leopoldo, 3 (1), p. 34-41, jan./jun. 2011.

JORGE NETO, Nagibe de Melo. Ativismo judicial, discricionariedade e controle: uma questão hermenêutica? Quaestio Iuris, Rio de Janeiro, v. 7, nº 2, 2014, p. 509-532.

KAUFMANN, Arthur. Filosofia do direito. Trad. António Ulisses Cortês. $3^{\text {a }}$ Ed. Lisboa: Fundação Calouste Gulbekian, 2009.

MACHADO, Martha Toledo. A proteção constitucional de crianças e adolescentes e os direitos humanos. Barueri, SP: Manole, 2003.

MELO, Eduardo Rezende. Direito e norma no campo da sexualidade na infância e na adolescência. In: UNGARETTI, Maria America (organizadora). Criança e adolescente: direitos, sexualidades e reprodução. São Paulo: ABMP, 2010, p. 43-59.

OLIVIERA, Bruno Queiroz; SANTIAGO, Nestor E. A. A crise da legalidade penal e a função do STJ na interpretação dos tipos penais. REDES - Revista Eletrônica Direito e Sociedade, Canoas, v. 6 , n. 2, set. 2018, p. 41-55.

PLACHI, Soraia Priscila, BRANCO, Paulo Gustavo Gonet, MENDES, Soraia da Rosa. Ativismo judicial e a presunção de inocência do adolescente infrator - análise da decisão do Supremo Tribunal Federal no HC 122.072/2014. Revista de Direito Brasileiro, São Paulo, v. 14, nº 6, maio/ago., 2016, p. 186-199. 
PRIORE, Mary Del. O cotidiano da criança livre no Brasil entre a colônia e o império. In: PRIORE, Mary Del (Organizadora). História das crianças no Brasil. $7^{\mathrm{a}}$ ed. São Paulo: Contexto, 2015, p. 84-106.

ROSA, Alexandre Morais da. O que é garantismo jurídico? Florianópolis: Habitus, 2003.

SABOIA, Jessica Ramos; SANTIAGO, Nestor E. A.. Garantismo e ativismo judicial: uma análise da presunção do estado de inocência e da sua relativização pelo STF. Revista Direitos Fundamentais e Democracia, Porto Alegre, v. 32, nº 2, mai-ago. 2018, p. 53-74.

SABOIA, Jéssica Ramos. A atuação política do Supremo Tribunal Federal e a (in)compatibilidade com a democracia brasileira. Revista de Direito Brasileira, São Paulo, v. 19, no 8, jan./abr., 2018, p. 335-347.

SOUZA, Solange Jobim e. Criança e adolescente: construção histórica e social nas concepções de proteção, direitos e participação. In: UNGARETTI, Maria America (organizadora). Criança e adolescente: direitos, sexualidades e reprodução. São Paulo: ABMP, 2010, p. 87-100.

SOUZA NETO, Manoel Onofre, AMARAL, Sasha Alves do. A tutela de urgência e a criança e o adolescente: em defesa de uma atuação especializada e efetiva. In: PAE KIM, Richard, SARAIVA, João Batista Costa (coordenação). Revista de Direito da Infância e da Juventude, ano 1, vol 1 - jan-jun/2013. São Paulo: ABMP, RT, 2013, p. 43-81.

STRECK, Lenio Luiz. Verdade e consenso: constituição, hermenêutica e teorias discursivas: da possibilidade à necessidade de respostas corretas em direito. $2^{\mathrm{a}}$ ed., rev. e ampl. Rio de Janeiro: Lumen Juris, 2008.

STRECK, Lenio Luiz; MOTTA, Francisco José Borges. Um debate com (e sobre) o formalismo valorativo de Daniel Mitidiero, ou "colaboração no processo civil" é um princípio?. Revista de Processo, v. 213, a. 37, nov. 2012, p. 13-34.

TRUBEK, David M. Max Weber sobre direito e ascensão do capitalismo. In: Revista Direito GV, v. 3, jan-jun 2007, p. 151-186.

VOLTAIRE. O preço da justiça. Trad. Acrísio Tôrres. $2^{\mathrm{a}}$ ed. São Paulo: Martins Fontes, 2006. 